\title{
ADAMLAB \\ Educational Agency Designs Voice Output Communication Aid
}

\author{
Gregory A. Turner \\ Adaptive Devices Applied Methods Laboratory (ADAMLAB) \\ Wayne County Regional Educational Service Agency \\ Wayne, MI 48184
}

\begin{abstract}
This paper gives a thumbnail sketch of the ADAMLAB project. The project has pioneered an entrepreneurial model in the governmental (public agency) sphere for the design and delivery of low-cost electronic assistive technology products to handicapped individuals for whom the otherwise high cost of the technology is prohibitive.
\end{abstract}

\section{ADAMLAB- a Unique Project for Special Education Technology}

ADAMLAB (Adaptive Devices Applied Methods Laboratory) is an innovative project for the design and manufacture of low-cost electronic and microcomputer technology for special education students who are mentally and physically challenged. ADAMLAB's particular specialty is voice output systems, in particular Voice Output Communication Aids (VOCA).

$A D A M L A B$ personnel include engineers, programmers, and other technical and data management staff. Responding to the perceived and voiced needs of special education teaching staff, $A D A M L A B$ designs equipment from the micro-component level up and then contracts local assembly firms for its manufacture. Revenues from the distribution of $A D A M L A B$ products nationally and internationally balance all expenses and provide funds for the provision of free equipment and services to students locally. Thus, custom engineering services are available to the local community at no cost to the taxpaying public.

\section{Wayne County Regional Educational Service Agency}

ADAMLAB's parent organization is the Wayne County Regional Educational Service Agency (RESA). The RESA is the level of educational administration and support services at the county level. Wayne County, which includes metropolitan Detroit, USA, is one of the nation's most populous counties. As an example of the services provided, WCRESA's Data Processing operation supports the thirty-four local school districts in the county for their finance and student record needs--one of the largest such operations for education in the whole country.

Data Processing's field engineering service was the birthing place for the RESA's special education technology engineering activities in the late 1970's. At that time, WCRESA was collaborating with Michigan State University's Artificial Language Laboratory in the development of synthetic voice applications for students in WCRESA's programs for the Severely Mentally and Severely Multiply Impaired. After several years, the engineering program was transplanted to WCRESA, eventually developing into the full blown ADAMLAB project in 1986. 


\section{The Wolf- Pioneer Low Cost VOCA}

From 1978 to 1984 , several generations of talking devices were prototyped, resulting finally in the development of the Wolf Voice Output Communication Aid. Hand held and batterypowered, the Wolf has a membrane touchpanel, on which overlays are positioned bearing pictures and symbols meaningful to the student user who presses these to activate corresponding synthetic voice messages--so, for example, a picture of a television could have the voice output: "I want to watch TV." The Wolf's electronics consist of the ADAMLABdesigned single board 8-bit microcomputer, with banked memory to augment the fundamental architecture in order to accommodate the data storage requirements for programmed vocabulary and for the installed software synthesizer. The synthesizer, the commercial Provoice product from First Byte Inc. (Torrance, CA), has a kinship to diphone systems in that its atomic units are digital samples. Besides English, the synthesizer can also generate Spanish, German, and French and we intend these languages to be available in the Wolf in the near future.

The principal ideas behind the Wolf device are low-cost, durability, and simplicity of use. As a case in point, the Wolf's original $1984 \$ 250$ cost was ten times less than the then $\$ 2,500$ average cost of comparably used equipment from private manufacturers--and indeed, only since 1990 are there available some commercial VOCAs in the one thousand dollar and under price range. Low cost has made the Wolf available and practicable for use to all the speech disability groups, including those in the severe categories for whom the purchase of multi-thousand dollar devices will always be controversial. As of mid 1994, over fifteen thousand Wolf units have been distributed.

\section{ADAMLAB as an Economic Model}

The Wolf is priced to recover direct costs (components and the cost of the contracted manufacturing, and miscellaneous "raw" costs like postage), associated ADAMLAB staff costs (including the one-time, at purchase custom vocabulary programming service), and pro-rated costs to cover loss, breakage, repair under warranty, on-going $R \& D$ costs, and costs associated with equipment re-capitalization.

In addition, a charge is added to provide funding for Wayne County-specific special education activities. So, for example, in 1992 the Assistive Technology Resource Center (ATRC) project was established with funding provided from these designated revenues. ATRC's evaluation, assessment, and consulting activities are carried out by a three person team, consisting of speech and occupational therapists and a computer systems consultant. Besides assisting local school districts in critical programs such as IEP, inclusion, vocational education, and transition, ATRC staff also engage in research-related activities. In 1993, a collaboration between ATRC, ADAMLAB, and students and faculty at Wayne State University's Department of Electrical Engineering resulted in the first place design win at the RESNA student competition. The design, called the Sequential Task Trainer, uses sensors and lighted and voice-output feedback to prompt and correct low-cognitive students in manual assembly tasks as typically found in sheltered workshop contexts. This field, technology products for vocational education, is fast emerging as one of the exciting new areas of application for assistive technology and rehabilitation.

ADAMLAB's positive revenue situation has allowed for the provision of no-charge repair services. Repair costs are typically not factored in to the cost of assistive technology products 
but these can be substantial. ADAMLAB's ability to provide repair at no-charge means that long-term maintenance of product by consumers is economically neutral to them.

$A D A M L A B$ is a "win-win" situation: appropriate technology is provided at very low costs to adequately meet the demands of the consuming public, at the same time yielding revenues sufficient to fund long-term maintenance of the equipment, to provide custom engineering and consulting services to local consumers, and to support on-going research and development to practically apply advances in technology to the needs of the handicapped.

\section{ADAMLAB Assistive Technology in the Nineties}

ADAMLAB's research agenda in the mid-nineties has resulted in a set of new products that utilize modern digital voice technology and highly integrated microchip architectures. The Hawk and Lynx VOCA devices provide the ultimate simplification in voice synthesis programming: just talk into the microphone. These devices continue the tradition of the Wolf: low-cost, minimalistic design for increased reliability and ease of use, and maximized availability to all speech-disabled populations. By their nature, these digital voice products also expand the potential market to take in non-English language applications and indeed, the demand for these products for use overseas is on the upswing, with Hawks and Lynxes currently in use in Israel, Lithuania, Hungary, and Denmark. 